\title{
Ceruloplasmin Gene Expression in the Murine Central Nervous System
}

\author{
Leo W.J. Klomp, ${ }^{*}$ Z. Shadi Farhangrazi, ${ }^{\ddagger}$ Laura L. Dugan, ${ }^{\ddagger}$ and Jonathan D. Gitlin* \\ $*$ Edward Mallinckrodt Department of Pediatrics and ${ }^{\ddagger}$ Department of Neurology, and the Center for the Study of Nervous System Injury, \\ Washington University School of Medicine, St. Louis, Missouri 63110
}

\begin{abstract}
Aceruloplasminemia is an autosomal recessive disorder resulting in neurodegeneration of the retina and basal ganglia in association with iron accumulation in these tissues. To begin to define the mechanisms of central nervous system iron accumulation and neuronal loss in this disease, cDNA clones encoding murine ceruloplasmin were isolated and characterized. RNA blot analysis using these clones detected a $3.7-\mathrm{kb}$ ceruloplasmin-specific transcript in multiple murine tissues including the eye and several regions of the brain. In situ hybridization of systemic tissues revealed cellspecific ceruloplasmin gene expression in hepatocytes, the splenic reticuloendothelial system and the bronchiolar epithelium of the lung. In the central nervous system, abundant ceruloplasmin gene expression was detected in specific populations of astrocytes within the retina and the brain as well as the epithelium of the choroid plexus. Analysis of primary cell cultures confirmed that astrocytes expressed ceruloplasmin mRNA and biosynthetic studies revealed synthesis and secretion of ceruloplasmin by these cells. Taken together these results demonstrate abundant cell-specific ceruloplasmin expression within the central nervous system which may account for the unique clinical and pathologic findings observed in patients with aceruloplasminemia. $(J$. Clin. Invest. 1996. 98:207-215) Key words: iron • ceruloplasmin $\bullet$ brain $\bullet$ retina $\cdot$ genetics
\end{abstract}

\section{Introduction}

Ceruloplasmin is an abundant serum $\alpha_{2}$-glycoprotein which contains $>95 \%$ of the copper found in human plasma. This protein is a multicopper oxidase which is synthesized in hepatocytes as a single-chain polypeptide and secreted as a holoprotein with six atoms of copper per molecule. Although copper does not affect the rate of synthesis or secretion of ceruloplasmin, a failure to incorporate copper during biosynthesis results in secretion of an unstable protein that lacks oxidase activity and is rapidly degraded in the serum $(1,2)$. In Wilson disease an inability to transfer copper into a common intracellular pool for holoceruloplasmin synthesis and biliary copper excretion results in a marked decrease in the serum ceruloplasmin concentration secondary to rapid turnover of

Address correspondence to Jonathan D. Gitlin, M.D., Department of Pediatrics, St. Louis Children's Hospital, One Children's Place, St. Louis, MO 63110. Phone: 314-454-6124; FAX: 314-454-4542; E-mail: gitlin@kidsa2.wustl.edu

Received for publication 26 February 1996 and accepted in revised form 15 April 1996.

J. Clin. Invest.

(c) The American Society for Clinical Investigation, Inc.

0021-9738/96/07/207/09 \$2.00

Volume 98, Number 1, July 1996, 207-215 the secreted apoprotein. Consistent with this concept, the Wilson disease gene has been cloned and shown to encode a cation transport P-type ATPase essential for copper transfer into the secretory pathway of the hepatocyte (3-5).

Recently, individuals have been identified with diabetes, retinal degeneration, and neurologic symptoms in association with a total absence of serum ceruloplasmin $(6,7)$. Molecular genetic analysis of these patients has identified specific inherited mutations in the ceruloplasmin gene (8-12). The presence of these mutations in conjunction with the clinical and pathological features indicates an essential role for ceruloplasmin in human biology. Examination of pathologic specimens from affected patients reveals normal histology of the hepatic parenchyma and normal hepatic copper content but a marked elevation in the liver iron concentration. The iron content of the pancreas is also increased with specific accumulation in the islets of Langerhans and selective loss of pancreatic beta cells (13). These findings suggest a direct role for ceruloplasmin in iron metabolism consistent with early work that identified this protein as a ferroxidase and with recent studies on the essential role of an homologous copper oxidase in iron metabolism in yeast (14-17).

Despite evidence of systemic iron overload, patients with aceruloplasminemia present with neurological symptoms due to progressive neurodegeneration of the retina and basal ganglia in association with iron accumulation in these tissues. This unique involvement of the central nervous system distinguishes aceruloplasminemia from other inherited and acquired iron storage disorders and implies that ceruloplasmin plays an essential role in normal brain iron metabolism. As very little, if any, ceruloplasmin crosses the blood-brain barrier under normal circumstances (18), we hypothesized that this protein might be synthesized locally within the central nervous system, and we have conducted the current study to examine this possibility.

\section{Methods}

Materials. Chemicals were purchased from Sigma Chemical Co. (St. Louis, MO). DNA restriction and modifying enzymes were purchased from Promega Corp. (Madison, WI) and used according to manufacturer's specifications. DME was obtained from GIBCO BRL (Grand Island, NY); bovine FCS was from Bio-Whittaker (Walkersville, MA); proteinase K, aprotinin, pepstatin, leupetin and endoglycosidase $\mathrm{H}$ were from Boehringer Mannheim Biochemicals (Indianapolis, IN); Hybond-N nylon membranes and ${ }^{14} \mathrm{C}$-labeled protein standards were from Amersham Corp. (Arlington Heights, IL); Fuji RX film was from Fisher Scientific (Pittsburgh, PA), and protein A beads were from Repligen Corp. (Cambridge, MA). All radionucleotides and radiolabeled amino acids were purchased from ICN Radiochemicals (Costa Mesa, CA). A rabbit anti-human ceruloplasmin polyclonal antiserum was obtained from Axell (Westbury, NY).

Cloning of murine ceruloplasmin. To isolate murine ceruloplasmin cDNA clones $\sim 6 \times 10^{5}$ recombinant clones from a murine liver cDNA library in $\lambda$ gt11 (Clontech, Palo Alto, CA) were screened using a ${ }^{32} \mathrm{P}$-labeled cDNA probe corresponding to nucleotides $1-612$ of 
the human ceruloplasmin cDNA (19). Positive clones were identified, and inserts were amplified by PCR using primers specific for sequences flanking the cloning sites of the phage arms (20). Amplified DNA was subcloned into pCRII (Invitrogen, San Diego, CA), and the complete nucleotide sequence of each clone was determined (21). Sequence data were analyzed using the PCGene software program from IntelliGenetics (Mountain View, CA).

$R N A$ analysis. $\mathrm{C} 57 \mathrm{BL} / 6 \mathrm{~J} \times \mathrm{CBA} / \mathrm{J}$ mice were purchased from Jackson Laboratories (Bar Harbor, ME) and housed in the animal care facility at St. Louis Children's Hospital. All mice were maintained on standard laboratory chow and kept in a windowless room on a $12 \mathrm{~h} / 12 \mathrm{~h}$ dark-light cycle. Individual organs from adult mice were isolated, pooled, and snap frozen in liquid nitrogen. RNA was isolated by dissolution of tissue or confluent monolayers of cells in guanidinium isothiocyanate followed by cesium chloride gradient centrifugation (22). RNA samples were denatured in formaldehyde containing buffer and electrophoresed in $1 \%$ agarose, $2.2 \mathrm{M}$ formaldehyde gels. The size of specific mRNA transcripts was determined using ${ }^{32} \mathrm{P}$-cRNA standards of known length. After electrophoresis the RNA was visualized by ethidium bromide staining to ensure that equivalent amounts of intact total RNA were present for each sample. RNA was then transferred to nylon by capillary blotting and immobilized by ultraviolet cross-linking. RNA blots were hybridized with ${ }^{32} \mathrm{P}$-labeled cRNA probes $\left(5 \times 10^{8} \mathrm{cpm} / \mu \mathrm{g}\right)$ as previously described (23). The murine ceruloplasmin cRNA probe used for this analysis corresponded to nucleotides 262-788 of the murine sequence. In all cases RNA blots were reprobed with a cRNA probe for $\beta$-actin to ensure that equivalent amounts of RNA were present in each lane.

In situ hybridization. In situ hybridization was performed according to the methodology of Simmons et al. (24) with modifications as described (20). Organs were removed en bloc from mice, rinsed in saline, and immersed in fixative solution containing $10 \%$ buffered formalin for $72 \mathrm{~h}$. Sections $(5 \mu \mathrm{m})$ were prepared and subsequently deparafinized and rehydrated in alcohol solutions of descending concentration (20). Before hybridization, sections were treated with proteinase $\mathrm{K}$ and acetic anhydride. For these studies, ceruloplasmin specific probes corresponding to nucleotides 268-788, 1347-1703, and 2209-2632 of the murine cDNA sequence were amplified by PCR, subcloned into pCRII, and sequenced to determine orientation. Sense and antisense cRNA probes were synthesized in $40 \mathrm{mM}$ Tris$\mathrm{HCl}, \mathrm{pH} 7.9,6 \mathrm{mM} \mathrm{MgCl}, 10 \mathrm{mM}$ DTT, $2 \mathrm{mM}$ spermidine with 0.5 $\mathrm{mM}$ unlabeled dNTPs, and ${ }^{35} \mathrm{~S}-\mathrm{UTP}$ as described (25). After transcription, unincorporated nucleotides were removed by gel filtration, and $3 \times 10^{7} \mathrm{cpm} / \mathrm{ml}$ of ${ }^{35} \mathrm{~S}$-cRNA was used for in situ hybridization. Hybridization was performed for $20 \mathrm{~h}$ at $60^{\circ} \mathrm{C}$ in $50 \%$ formamide, $10 \%$ dextran sulfate, $0.3 \mathrm{M} \mathrm{NaCl}, 1 \times$ Denhardt's solution, $10 \mathrm{mM}$ Tris-HCl, $\mathrm{pH}$ 8.0, $1 \mathrm{mM}$ EDTA, $0.1 \mathrm{mg} / \mathrm{ml} \mathrm{tRNA}$, and $0.1 \mathrm{M}$ DTT. After hybridization, slides were treated with ribonuclease A $(20 \mu \mathrm{g} / \mathrm{ml})$ at $37^{\circ} \mathrm{C}$ for $1 \mathrm{~h}$ and washed as described (20). Slides were then dipped in Kodak NTB2 liquid autoradiography emulsion, exposed for 5-22 d at $4^{\circ} \mathrm{C}$, counterstained with haematoxylin and eosin, mounted with DPX-mountant, and examined and photographed using bright and dark-field microscopy.

Primary cell culture. To establish glial and neuronal cell cultures, brain tissue was dissected, minced, dispersed into single cells and plated in 35-mm plastic dishes as previously described (26). Glial cells were obtained from the cortices of 1- or 2-d-old mice. At this age, the progenitor cells have lost the ability to differentiate into neuronal cells, giving rise to a pure glia cell preparation which contains $>95 \%$ astrocytes (26). Microglia did not adhere to the plate and were rinsed away when medium was replaced. Glia-enriched cell cultures reached confluency after $10 \mathrm{~d}$ in culture. Neuronal cells were obtained from E14-E15 murine embryonic brain tissue. After $2 \mathrm{~d}$ in culture glia cell proliferation was inhibited by the addition of $10 \mu \mathrm{M}$ cytosine arabinoside. Based on the characteristic morphology, neuronal and glial cell cultures were assessed to be at least $95 \%$ pure before each experiment. All experiments were performed at $2 \mathrm{wk}$ after plating the cells.

Metabolic labeling and immunoprecipitation. Primary cell cultures were labeled in DME containing $250 \mu \mathrm{Ci} / \mathrm{ml}$ of ${ }^{35} \mathrm{~S}$-methionine and ${ }^{35} \mathrm{~S}$-cysteine. In some experiments, tunicamycin was added $4 \mathrm{~h}$ before addition of the radiolabel to a final concentration of $4 \mu \mathrm{g} / \mathrm{ml}$. Cells were lysed in PBS containing $1 \%$ Triton X-100, 0.1\% SDS, $1 \mathrm{mM}$ EDTA, $2 \mathrm{mM}$ PMSF, $2 \mu \mathrm{g} / \mathrm{ml}$ aprotinin, $1 \mu \mathrm{g} / \mathrm{ml}$ pepstatin, and $1 \mu \mathrm{g} /$ $\mathrm{ml}$ leupeptin. For immunoprecipitation, an equal volume of PBS containing $1 \%$ Triton $\mathrm{X}-100,1 \%$ SDS, $0.5 \%$ sodium deoxycholate, $0.5 \%$ BSA, $2 \mathrm{mM}$ PMSF, $2 \mu \mathrm{g} / \mathrm{ml}$ aprotinin, $1 \mu \mathrm{g} / \mathrm{ml}$ pepstatin, and $1 \mu \mathrm{g} / \mathrm{ml}$ leupeptin was added to the cell lysates or media, and these were then precleared overnight with $5 \mu \mathrm{l}$ of preimmune rabbit serum followed by a $1 \mathrm{~h}$ incubation with protein A sepharose beads. Ceruloplasmin was subsequently immunoprecipitated from the supernatant using 5 $\mu l$ of a rabbit polyclonal antisera raised against human ceruloplasmin (19). Immune complexes were precipitated with protein A beads, released by boiling in sample buffer, and analyzed by SDS-PAGE under reducing conditions. In some experiments, immunoprecipitated ceruloplasmin was eluted from the protein A beads in $50 \mathrm{mM}$ Tris$\mathrm{HCl}, \mathrm{pH} 6.8,0.5 \%$ SDS, $0.1 \mathrm{M} \beta$-mercaptoethanol at $100^{\circ} \mathrm{C}$ for $5 \mathrm{~min}$. Digestion with endoglycosidase $\mathrm{H}(50 \mathrm{mU})$ was then performed in 0.5 vol of $0.15 \mathrm{M}$ sodium acetate, $\mathrm{pH}$ 6.0, $2 \mathrm{mM}$ PMSF, $1 \mu \mathrm{g} / \mathrm{ml}$ leupeptin, $1 \mu \mathrm{g} / \mathrm{ml}$ pepstatin for $16 \mathrm{~h}$ at $37^{\circ} \mathrm{C}$. In all cases, the amount of sample loaded per lane was adjusted by measuring trichloroacetic acid precipitable radioactivity (23). ${ }^{14} \mathrm{C}$-methylated molecular size markers were included in all gels, and after electrophoresis, gels were impregnated with 2,5-diphenyloxazole and dried for fluorography on XR film.

\section{Results}

To isolate cDNA clones encoding murine ceruloplasmin, a murine liver cDNA library was screened using a human ceruloplasmin cDNA probe. Several overlapping clones were isolated and the nucleotide sequence of each determined. This sequence encompassed 3363 nucleotides including an open reading frame of 3,185 bases, a $5^{\prime}$ untranslated region of 105 nucleotides and 69 nucleotides of $3^{\prime}$ untranslated sequence (GenBank accession \#U49430). As can be seen from the derived amino acid sequence in Fig. 1, murine ceruloplasmin is a protein of 1,043 amino acids preceeded by a 19 amino acid signal peptide. Comparison of the murine sequence to human and rat ceruloplasmin reveals 85 and $89 \%$ amino acid identity, respectively, with complete conservation of the amino acid ligands essential for binding of the six copper molecules (23, 27) (Fig. 1). Of seven potential N-linked glycosylation sites in human ceruloplasmin, five are conserved in the murine sequence as well as an additional sixth site at amino acid 625 .

Ceruloplasmin gene expression. To determine the tissuespecific expression of murine ceruloplasmin, total RNA was isolated from adult murine tissues, and RNA blot analysis was performed using a murine ceruloplasmin cRNA probe. This analysis revealed a transcript of $3.7-\mathrm{kb}$ which was readily detected in total RNA from murine liver (Fig. $2 A$, lane 1 ). An identical size ceruloplasmin-specific transcript was also detected in RNA isolated from murine spleen, lung, kidney, and testis, but not in RNA samples from skeletal muscle or small intestine (Fig. $2 \mathrm{~A}$ ). Further analysis of RNA from other systemic tissues including thymus, heart, and various regions of the gastrointestinal tract, did not reveal ceruloplasmin-specific transcripts (data not shown).

To analyze ceruloplasmin gene expression in the central nervous system, RNA was isolated from murine eye and brain and subjected to similar analysis. As can be seen in Fig. $2 \mathrm{~B}$, an abundant $3.7-\mathrm{kb}$ transcript was detected in total RNA isolated from murine eye as well as cortex, cerebellum, and midbrain. 


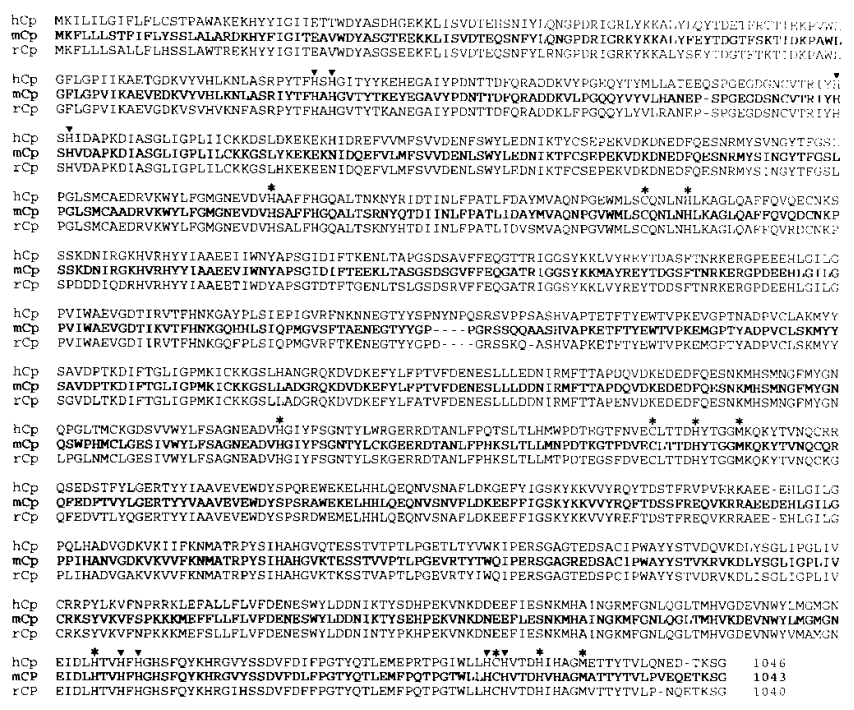

Figure 1. Derived amino acid sequence of murine ceruloplasmin. The open reading frame in the overlapping cDNA clones was translated and aligned with the amino acid sequences of human and rat ceruloplasmin. The first 19 amino acid residues form the putative signal sequence. Gaps (-) were introduced to obtain maximal identity. * indicate the essential amino acid residues forming the type I copper ligands; $\nabla$ indicates the amino acids essential for formation of the trinuclear copper cluster.

A similar size transcript was also detected in RNA isolated from total brain tissue of 1-d-old mice (Fig. 2 B, lane 5). No size differences were observed in ceruloplasmin mRNA expression in these tissues when compared to findings from liver or other systemic organs. In RNA samples from lung and eye a second, less abundant 4.3-kb transcript was also observed (Fig. 2). Further analysis using RNA isolated from peripheral blood cells failed to detect any ceruloplasmin transcripts indicating that the results observed for individual organs were not due to ceruloplasmin gene expression in leukocytes from residual blood at time of RNA isolation (data not shown).

To characterize the cell-specific expression of the murine ceruloplasmin gene, in situ hybridization was performed on all tissues in which a ceruloplasmin transcript was detected. As anticipated, when a section of adult liver was studied, abundant ceruloplasmin mRNA was detected in hepatocytes distributed homogeneously throughout the hepatic parenchyma with no signal present in the endothelium or biliary epithelium surrounding the portal spaces (Fig. 3, $A$ and $B$ ). In all these studies no signal was detected using the corresponding sense strand cRNA probes or after pretreatment of the slides with RNAse A (data not shown). Ceruloplasmin mRNA was detected in the splenic reticuloendothelial system concentrated in the marginal zone and scattered throughout the red pulp (Fig. 3, $C$ and $D$ ). On higher power this expression was found to be confined to macrophages with no ceruloplasmin transcripts in endothelial cells (data not shown). No ceruloplasmin expression was observed in lymphocytes constituting the white pulp of lymphoid follicles (Fig. 3, $C$ and $D$ ). In the lung, abundant ceruloplasmin gene expression was observed in ciliated and nonciliated epithelium lining the bronchioles and larger airways (Fig. 3, $E$ and $F$ ). Pulmonary ceruloplasmin gene expression was confined to this epithelium with no expression detected in the lung parenchyma or associated blood vessels.

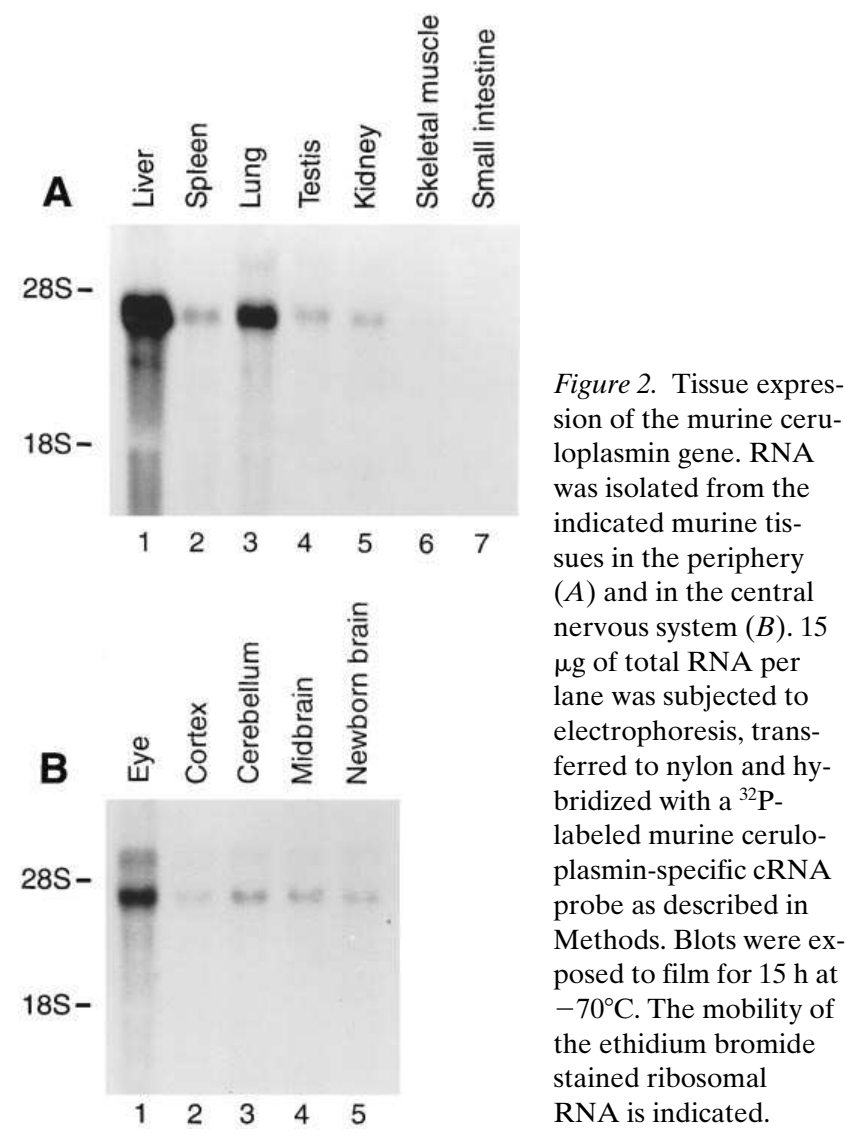

Less abundant but distinct ceruloplasmin gene expression was also detected by in situ hybridization in testicular Leydig cells and the epithelium of the distal collecting tubules of the kidney (data not shown).

Abundant ceruloplasmin gene expression was detected in total RNA from the murine eye. To determine if this expression was within the central nervous system, in situ hybridization was performed. This analysis revealed cell-specific ceruloplasmin mRNA in the retina confined to the Müller cells in the inner nuclear layer and to astrocytes within the ganglion cell layer (Fig. $4 A$ and $B$ ). At higher power, no ceruloplasmin gene expression was observed in any of the multiple neuronal cell types within the retinal tissue which were readily identified as larger nucleated cells. The scattered signal seen on darkfield in the region of the rods and cones is nonspecific due to grains from the underlying retinal pigment epithelial cells and was observed on these slides before hybridization (Fig. $4 \mathrm{~B}$ ). In addition to the retinal glia, nonpigmented epithelial cells lining the choroid layer in the anterior part of the eye were found to express ceruloplasmin mRNA, and this was most clearly observed in the ciliary body (data not shown).

To characterize the cells involved in ceruloplasmin gene expression in the brain, sagittal and coronal sections through different parts of the murine brain were analyzed by in situ hybridization using ceruloplasmin-specific cRNA probes. As can be seen in Fig. 5, cell-specific expression of ceruloplasmin mRNA in the adult brain was detected in epithelial cells of the pia-arachnoid, the ependymal cells lining the ventricles, and the choroid plexus (Fig. 5, $A-E$ ). In these studies, the brain parenchyma was also consistently labeled in a diffuse punctate manner suggesting that ceruloplasmin gene expression was lo- 

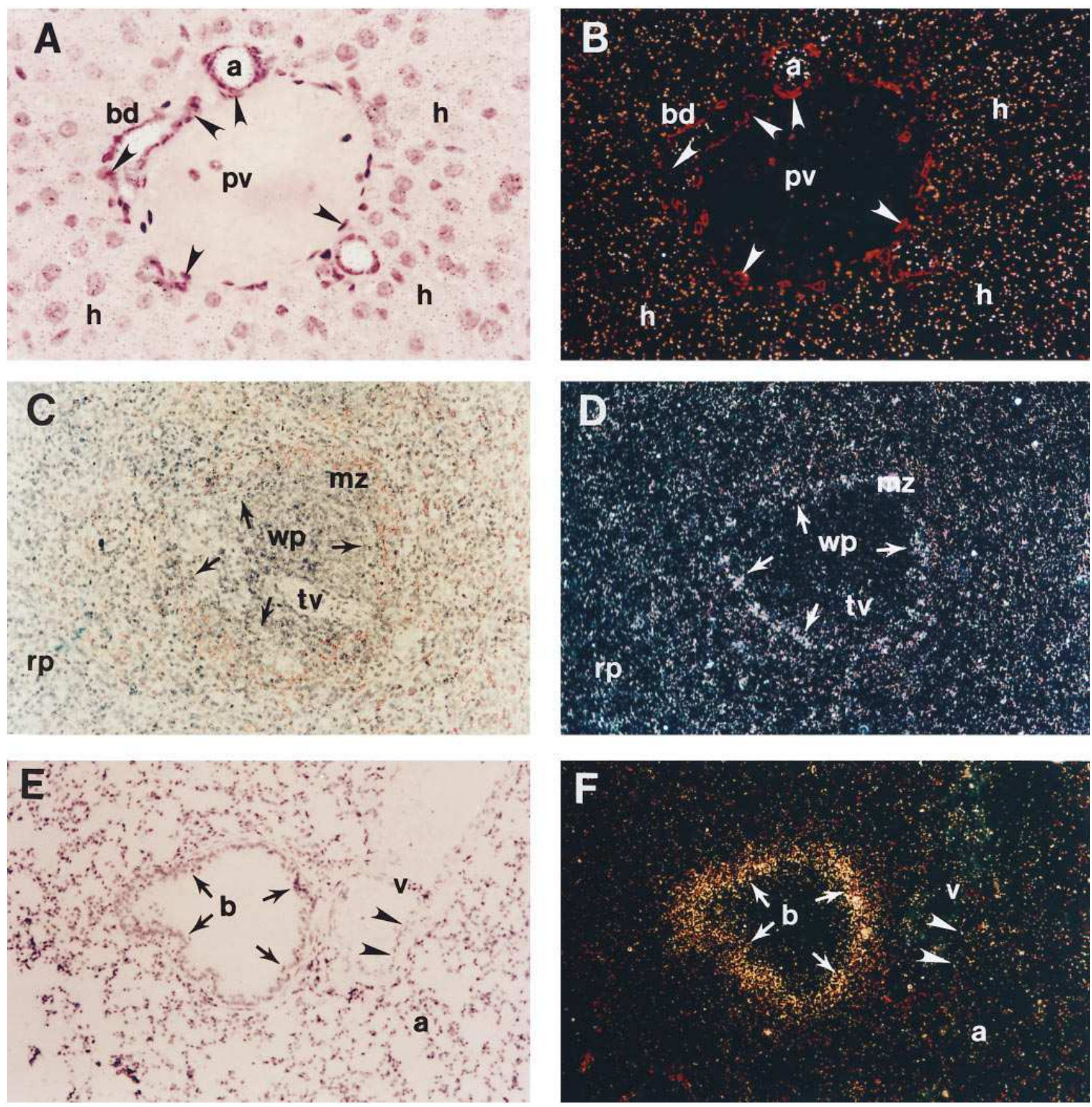

Figure 3. In situ hybridization of murine liver, spleen, and lung with ceruloplasmin-specific cRNA probes. Tissues were prepared as described in Methods and analyzed following in situ hybridization using bright $(A, C$, and $E)$ and dark-field $(B, D$, and $F)$ microscopy. Murine liver $(A$ and $B)$ with portal vein $(p v)$, bile duct $(b d)$, biliary artery $(a)$, and hepatocytes $(h)$ as shown. Arrowheads indicate endothelium and biliary epithelium. Original magnification: $\times 640$. Murine spleen $(C$ and $D)$ with white pulp $(w p)$, red pulp $(r p)$, marginal zone $(m z)$, and trabecular vein $(t v)$ as indicated. Arrows highlight macrophages of reticuloendothelial system concentrated in marginal zone. Original magnification: $\times 125$. Murine lung $(E$ and $F$ ) with bronchiole $(b)$, blood vessel $(v)$, and alveoli $(a)$ as indicated. Arrows indicate the bronchiolar epithelial cells and arrowheads point to endothelial cells lining the blood vessel. Original magnification: $\times 160$.

calized to a specific cell type in this tissue (Fig. $5 \mathrm{D}$ ). This pattern was observed throughout the brain parenchyma, including the basal ganglia and, upon careful examination, was found to be largely confined to astrocytes in close association with cerebral microvasculature (Fig. $5 F$ ). In addition, some astrocytes not obviously associated with the microvasculature were found to express ceruloplasmin mRNA but in no case was specific signal observed in neurons (data not shown).
Ceruloplasmin biosynthesis. Ceruloplasmin gene expression in astrocytes within the retina and brain was further examined using primary cultures of murine neurons and glia. Total RNA was isolated from these primary cell cultures, and ceruloplasmin gene expression was examined by RNA blot analysis. As shown in Fig. $6 A$, this analysis revealed abundant expression of a 3.7-kb ceruloplasmin-specific mRNA in RNA isolated from primary glia cells. A much less abundant $4.3-\mathrm{kb}$ 


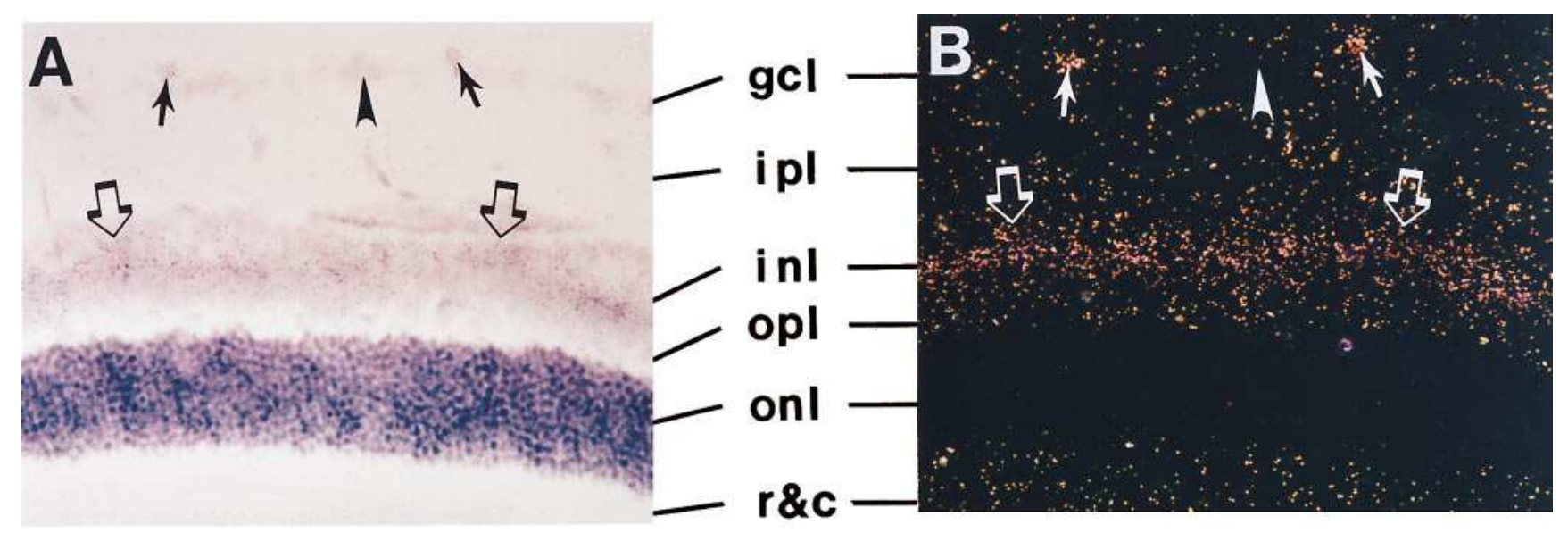

Figure 4. In situ hybridization of the murine retina with ceruloplasmin-specific cRNA probes. In situ hybridization was performed as described in Methods, and slides were examined with bright-field $(A)$ and corresponding darkfield $(B)$ microscopy. Murine retina $(A$ and $B)$ with rods and cones $(r \& c)$, outer nuclear layer (onl), outer plexiform layer (opl), inner nuclear layer (inl), inner plexiform layer (ipl), and ganglion cell layer $(\mathrm{gcl})$ as shown. Arrows indicate astrocytes in the ganglion cell layer; the arrowhead indicates a ganglion cell; the open arrows demarcate ceruloplasmin expression in Müller cells in the $i n l$. Original magnification: $\times 320$.

transcript identical to that observed in murine lung and eye was also detected in glial cell RNA, and both transcripts were absent in the RNA from neuronal cells. Reprobing of this blot with a $\beta$-actin-specific probe confirmed that equivalent amounts of total RNA were loaded in each lane (Fig. $6 \mathrm{~B}$ ).

The availability of glia cell cultures expressing the ceruloplasmin gene permitted study of ceruloplasmin biosynthesis and secretion. Primary glial and neuronal cells were pulselabeled for $90 \mathrm{~min}$, and cell lysates were immunoprecipitated with an antibody to human ceruloplasmin. A protein of 132$\mathrm{kD}$ was detected by this method in cell lysates from the glial but not the neuronal cells (Fig. $6 C$ ). The specificity of the antisera was confirmed by preincubation with human ceruloplasmin before immunoprecipitation (Fig. $6 C$, lane 1 ). No specific band was seen when lysates were immunoprecipitated with preimmune sera (data not shown).

To further examine the biosynthesis and secretion of murine ceruloplasmin in these glial cell cultures, pulse-chase studies were performed. These data revealed that murine ceruloplasmin was synthesized as a precursor polypeptide of $130-\mathrm{kD}$ apparent molecular mass which was converted after $15 \mathrm{~min}$ to a mature peptide of $132-\mathrm{kD}$ (Fig. $7 A$ ). Starting at $15 \mathrm{~min}$, but more apparent after $1 \mathrm{~h}$ of chase, this $132-\mathrm{kD}$ band was also detected in the culture medium. Secretion of the $132-\mathrm{kD}$ species was almost complete after $2 \mathrm{~h}$ of chase, although some of the $130-\mathrm{kD}$ band remained intracellular at this time point (Fig. $7 \mathrm{~A}$ ). In chase incubations up to $8 \mathrm{~h}$, this $132-\mathrm{kD}$ band was almost completely recovered in the medium with $<5 \%$ of the total ceruloplasmin-specific radioactivity remaining as the intracellular 130-kD band (data not shown).

To directly compare the posttranslational modification and secretion of ceruloplasmin in glia to that observed in hepatocytes, further biosynthetic studies were performed. The derived amino acid sequence of murine ceruloplasmin reveals multiple potential N-linked glycosylation sites, and, consistent with this data, tunicamycin treatment of glial cells before metabolic labeling and immunoprecipitation resulted in a mobility shift to a $120-\mathrm{kD}$ species, in good agreement with the predicted molecular mass (Fig. 7 , lanes 1 and 2). Treatment of the immunoprecipitated ceruloplasmin with endoglycosidase $\mathrm{H}$ re- sulted in a similar shift of apparent molecular weight with no difference in size observed between samples digested from control or tunicamycin treated cells (Fig. $7 \mathrm{~B}$, lanes 3 and 4). When this experiment was repeated after a 30 -min chase period the $132-\mathrm{kD}$ polypeptide was now apparent in the cell lysates (Fig. $7 \mathrm{~B}$, lane 5) and this mature form was found to be resistant to endoglycosidase $\mathrm{H}$ digestion (Fig. $7 \mathrm{~B}$, lane 6 ), indicative of modification of $\mathrm{N}$-linked oligosaccharide chains in the medial Golgi before ceruloplasmin secretion.

\section{Discussion}

Aceruloplasminemia is a newly recognized disorder of iron metabolism resulting from inherited mutations in the ceruloplasmin gene. The most striking and unique feature of this disease is the progressive neurodegeneration which results in the clinical presentation of dementia, dysarthria, and dystonia. Although iron is an abundant and essential trace metal in the brain, other acquired and inherited disorders of iron overload do not effect iron metabolism or turnover in the brain except in regions lacking a blood-brain barrier $(28,29)$. Consistent with this concept, previous studies in developing animals revealed that the acquisition and redistribution of iron in the brain is largely independent of iron metabolism in the periphery $(30,31)$. As brain iron homeostasis is not perturbed by abnormalities in systemic iron metabolism, the clinical and pathologic observations in aceruloplasminemia suggest that ceruloplasmin has a unique and direct role in normal iron metabolism in the human central nervous system. Although transferrin and other proteins involved in systemic iron metabolism are expressed in the brain, the function of these proteins in the central nervous system is unknown, and the molecular mechanisms regulating iron metabolism in the brain remain unidentified (32).

Consistent with the concept that ceruloplasmin is essential for brain iron metabolism, the data in this study demonstrate abundant ceruloplasmin gene expression at both the brainCSF (choroid plexus) barrier and the blood-brain barrier. Specifically, the expression of ceruloplasmin by astrocytes within the retina and throughout the cerebral microvasculature re- 

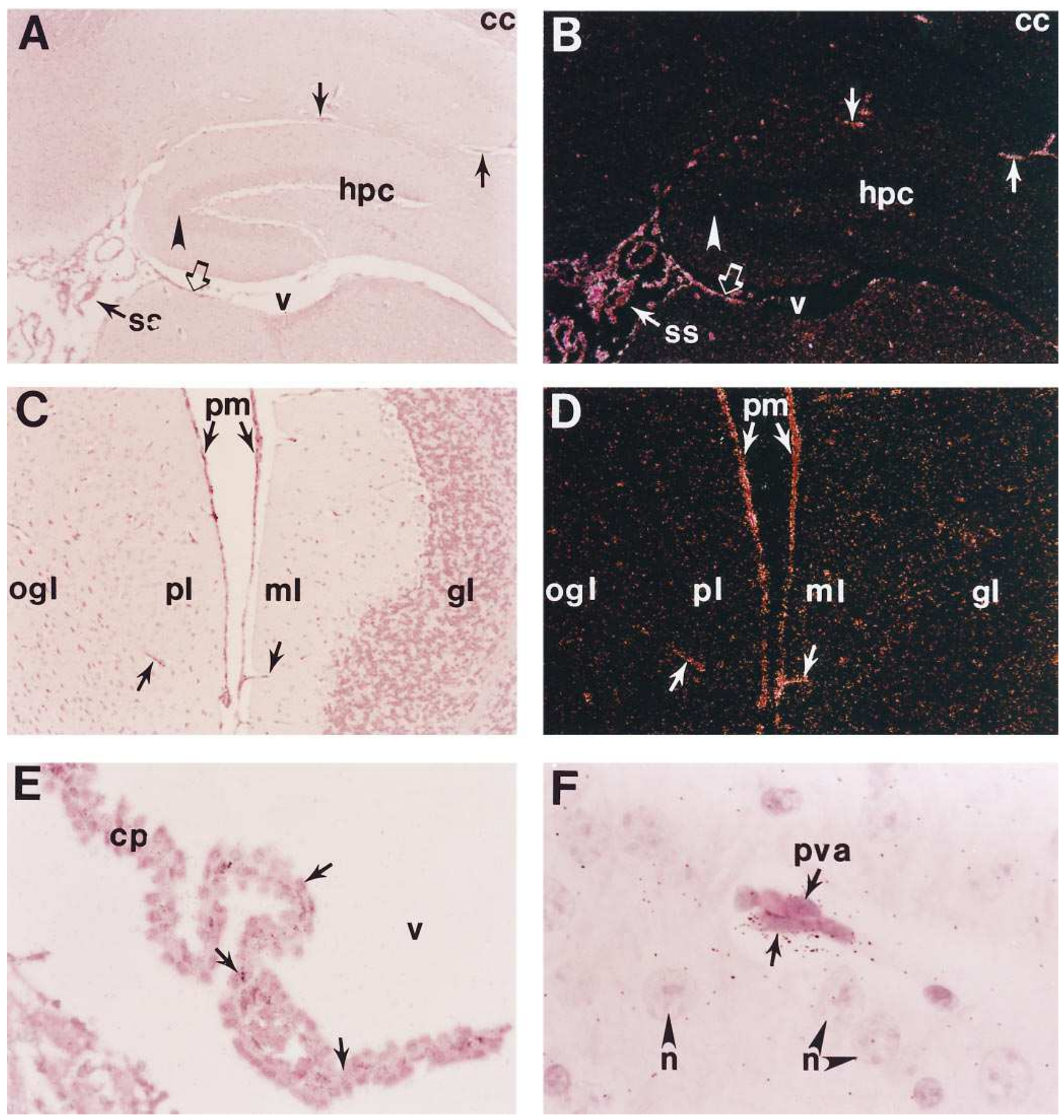

Figure 5. In situ hybridization of murine brain with ceruloplasmin-specific cRNA probes. In situ hybridization was performed as described in Methods and slides examined with bright-field $(A, C, E$, and $F)$ and corresponding dark-field $(B$ and $D)$ microscopy. Exposures of sagittal sections of adult mouse brain $(A-D)$ and higher magnification of choroid plexus $(E)$ and brain parenchyma $(F)$ as shown. Murine cortex and hippocampus $(A$ and $B)$ and cortex and cerebellum $(C$ and $D)$ with corpus callosum $(c c)$, hippocampus $(h p c)$, ventricle $(v)$, subarachnoid space $(s s)$, pia mater $(\mathrm{pm})$, outer granular layer $(\mathrm{ogl})$, plexiform layer $(\mathrm{pl})$, molecular layer $(\mathrm{ml})$, and granular layer $(\mathrm{gl})$ as indicated. The arrowhead illustrates neurons in the granule cell layer of the dentate gyrus of the hippocampus; the arrows demarcate epithelial cells of the pia and arachnoid with associated large blood vessels; the open arrow points to ependymal cells in the ventricle. Original magnifications: $\times 64(A$ and $B), \times 125(C$ and $D)$. $(E$ and $F$ ) ventricle $(v)$, choroid plexus $(c p)$, neuronal cells $(n)$, perivascular astrocytes $(p v a)$; Arrows point to epithelial cells of the choroid plexus $(E)$ and to astrocytes in association with the brain microvasculature $(F)$. Original magnification: $\times 400(E), \times 1,000(F)$.

veals that this protein is produced behind the blood-brain barrier suggesting that the absence of this expression in affected patients may account for the iron accumulation in these tissues (see below). The specific pattern of ceruloplasmin gene ex- pression in the retina was identical to that observed for actin gene expression in Müller cells and astrocytes in the murine retina (33). The expression in the brain is not observed in all astrocytes but rather identifies a unique subpopulation of 

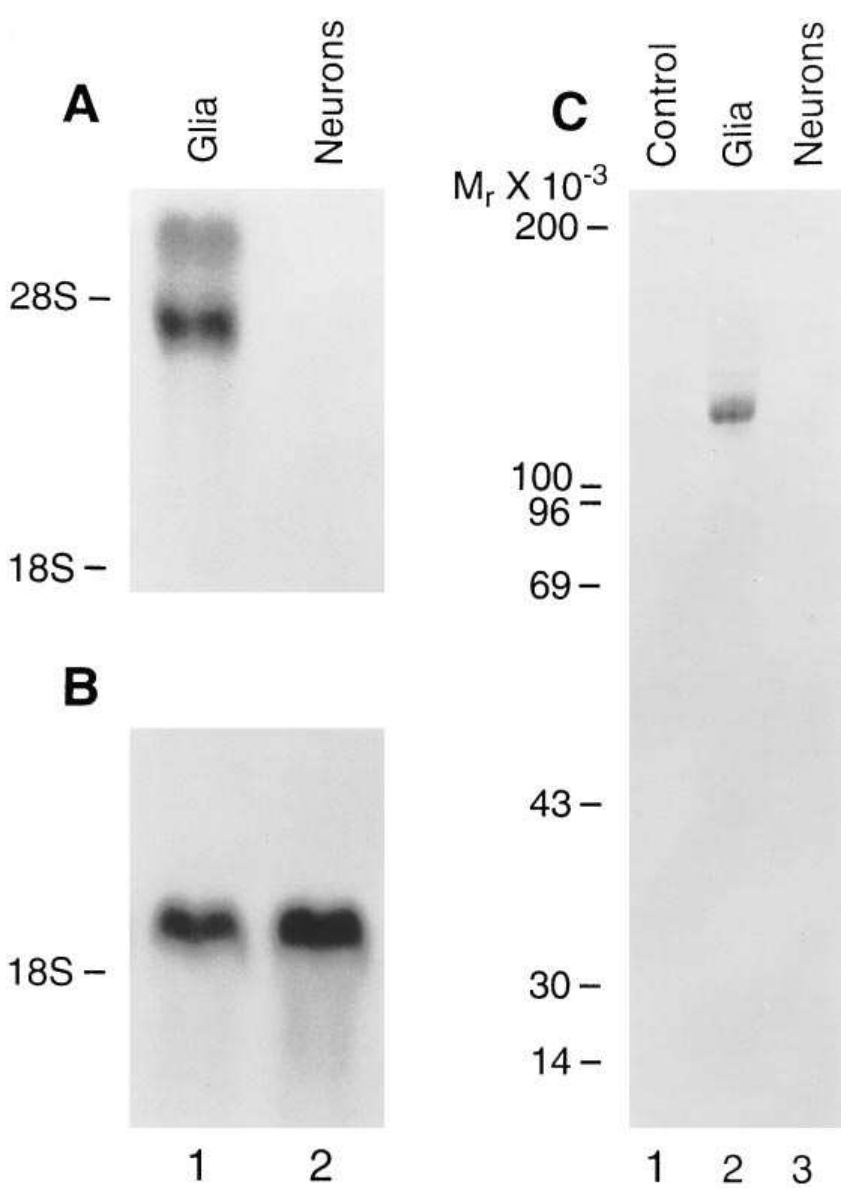

Figure 6. Expression of ceruloplasmin in primary cell cultures. Glial and neuronal cells were prepared as described in Methods. (A) RNA blot containing $15 \mu \mathrm{g}$ of total RNA isolated from primary cell cultures and hybridized with a ${ }^{32} \mathrm{P}$-labeled murine ceruloplasmin-specific cRNA probe. Blot was exposed for $15 \mathrm{~h}$ to film at $-70^{\circ} \mathrm{C}$. (B) blot was stripped and reprobed with a ${ }^{32} \mathrm{P}$-labeled murine $\beta$-actin cRNA probe and exposed to film for $1 \mathrm{~h}$ at $-70^{\circ} \mathrm{C}$. The mobility of the ethidium bromide stained ribosomal RNA species is indicated. (C) Newly synthesized proteins in confluent dishes of glia (lanes 1 and 2) and neurons (lane 3) were labeled with ${ }^{35} \mathrm{~S}$-methionine and ${ }^{35} \mathrm{~S}$-cysteine for $90 \mathrm{~min}$. Equal amounts of radioactivity were subjected to immunoprecipitation with anti-human ceruloplasmin antisera with (control, lane 1 ) or without (lanes 2 and 3 ) before incubation with $45 \mu \mathrm{g}$ of human ceruloplasmin. Immunoprecipitates were analyzed on $7.5 \%$ SDS-PAGE as described, and $M_{\mathrm{r}}$ markers are indicated.

these glial cells predominantly surrounding the microvasculature. Astrocytes in this region have been shown to contribute directly to the blood-brain barrier, and ceruloplasmin gene expression appears to be a unique molecular marker for these

Figure 7. Ceruloplasmin biosynthesis and secretion in glia cells. $(A)$ Confluent dishes of primary glial cells were incubated with ${ }^{35} \mathrm{~S}$-methionine and ${ }^{35} \mathrm{~S}$-cysteine for $15 \mathrm{~min}$ and chased in medium containing excess methionine and cysteine for the indicated time periods. Ceruloplasmin was immunoprecipitated from cell lysates $(I C)$ and media $(E X)$ and analyzed on $7.5 \%$ SDS-PAGE as described in Methods. $(B)$ Confluent dishes of primary glia were incubated for $4 \mathrm{~h}$ in the presence $(+)$ (lanes 3,4,7, and 8 ) or absence (-) (lanes 1,2,5, and 6) of $4 \mu \mathrm{g} / \mathrm{ml}$ tunicamycin $(\mathrm{Tm})$. Subsequently, cells were incubated with ${ }^{35} \mathrm{~S}$-methionine and ${ }^{35} \mathrm{~S}$-cysteine for $15 \mathrm{~min}$ and chased for 0
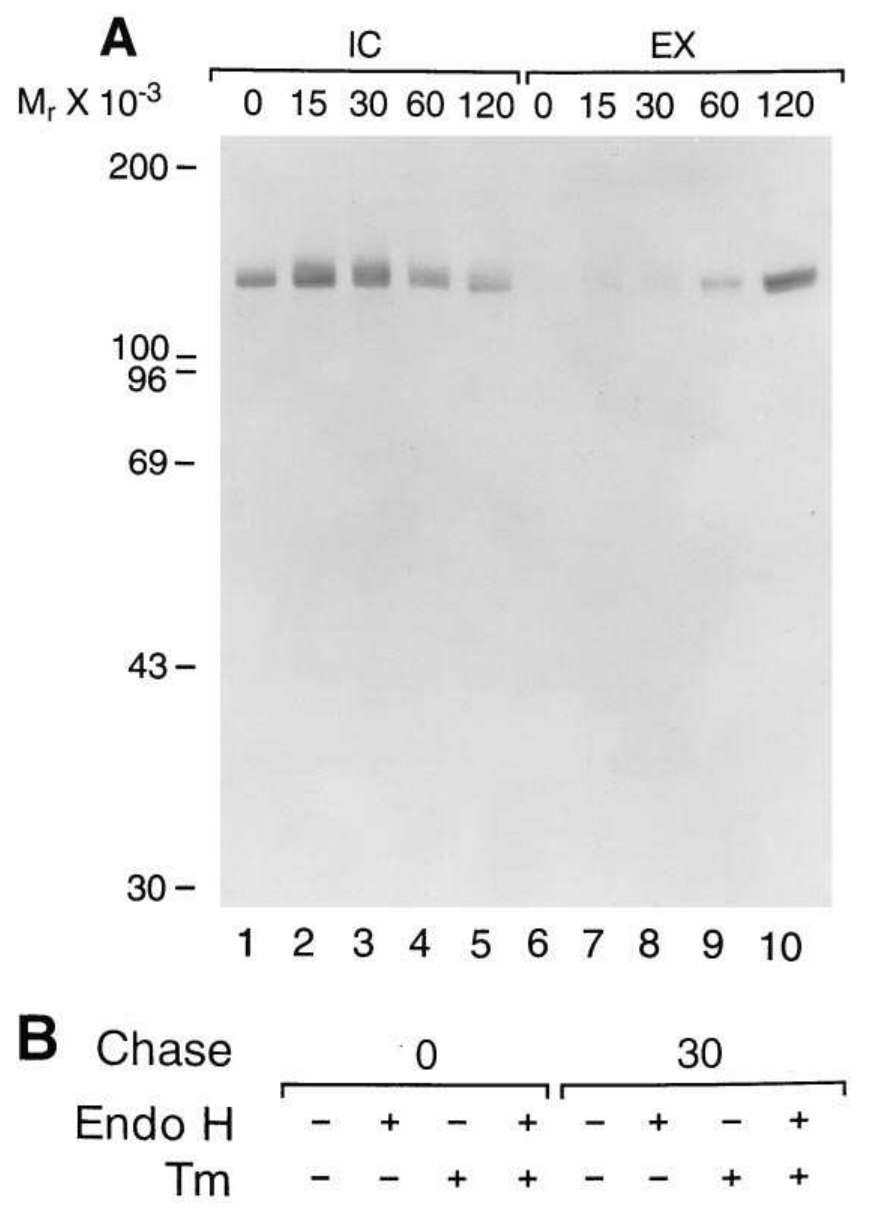

$\mathrm{M}_{\mathrm{r}} \times 10^{-3}$

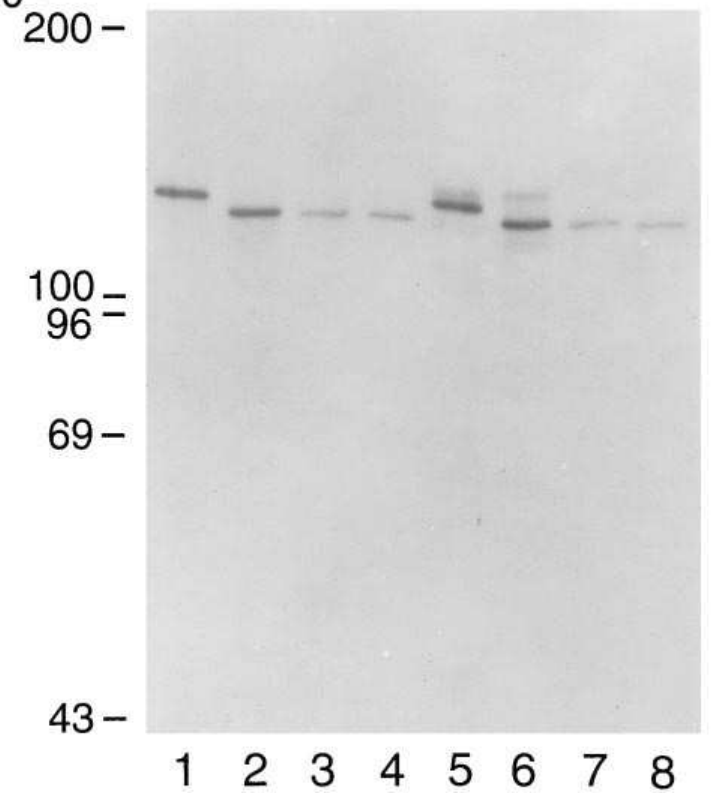

(lanes 1-4) or 30 min (lanes 5-8) in medium containing excess methionine and cysteine. If applicable, tunicamycin was continuously present during the pulse and chase periods. Ceruloplasmin was immunoprecipitated from aliquots of cell lysates. In this experiment the radioactivity in the samples corresponding to lanes $3,4,7$, and 8 was $50 \%$ of that in lanes $1,2,5$, and 6 . The immunoprecipitates were incubated in digestion buffer with $(+)$ (lanes $2,4,6$, and 8 ) or without $(-)$ (lanes $1,3,5$, and 7) endoglycosidase $\mathrm{H}$ for $16 \mathrm{~h}$ at $37^{\circ} \mathrm{C}$ and analyzed on $6 \%$ SDS-PAGE as described in Methods. 
cells (34). The biosynthesis and secretion of ceruloplasmin at these sites is confirmed by the observations in primary cultures since previous characterization has revealed that the glial cells obtained in this fashion are highly enriched in astrocytes (>95\%) (26). Although oligodendrocytes are also present in these preparations $(<5 \%)$, in situ hybridization of the primary cell cultures revealed abundant ceruloplasmin mRNA in the majority of cells, consistent with astrocyte-specific expression (data not shown). These observations are consistent with previous reports of ceruloplasmin gene expression in the rat choroid plexus and ceruloplasmin synthesis in astrocyte cultures from adult rat brain $(35,36)$. The observation that transferrin is synthesized in oligodendrocytes (32) indicates that, in contrast to the liver, distinct cell types are responsible for the biosynthesis of ceruloplasmin and transferrin in the central nervous system.

The marked homology of murine and human ceruloplasmin reported here implies species conservation of function and suggests that these findings will be relevant to understanding the role of ceruloplasmin in human iron metabolism. In support of this concept, extrahepatic ceruloplasmin gene expression was observed in multiple murine systemic tissues analogous to observations on ceruloplasmin gene expression in human tissues $(37,38)$. In those tissues expressing ceruloplasmin, a larger 4.3-kb ceruloplasmin-specific transcript was also observed at varying levels of expression. RNAse protection experiments using probes derived from the coding region of murine ceruloplasmin revealed that this larger transcript was not due to variations within the coding region (data not shown). Ceruloplasmin transcripts were detected in splenic reticuloendothelial cells concentrated in the marginal zones of the periarteriolar lymphoid sheets, consistent with data demonstrating ceruloplasmin gene expression in rat macrophages and human macrophage cell lines $(39,40)$. In the spleen, these cells are responsible for the efflux of iron into the plasma after phagocytosis and digestion of senescent erythrocytes. Previous studies in copper-deficient animals suggested a direct role for ceruloplasmin in iron efflux from the reticuloendothelial system via ferrous iron oxidation, and it is possible that local ceruloplasmin production in these cells facilitates this process (14-15).

Murine ceruloplasmin gene expression was also detected in the bronchiolar epithelium of the lung. A similar observation in the murine and baboon lung has recently been reported, and, taken together, these data suggest that this epithelium is the site of synthesis of ceruloplasmin detected in human pulmonary lavage fluid $(41,42)$. Pulmonary ceruloplasmin gene expression is increased during inflammation and hyperoxia, and these data suggest that ceruloplasmin may function as an antioxidant in the airways mediated via the ferroxidase activity $(39,43)$. High affinity iron acquisition from the environment is an essential determinant of bacterial virulence and expression of ceruloplasmin in this epithelium may also represent an important host-defense to limit ferrous iron availability to invading pathogens (44).

The mechanisms of systemic iron accumulation in aceruloplasminemia are presumed to result from rapid ferrous iron uptake in the liver, pancreas, and other tissues due to the loss of ceruloplasmin ferroxidase activity. This would be consistent with kinetic observations made in copper-deficient animals and implies that the oxidation of iron for subsequent binding to transferrin is an essential function of ceruloplasmin $(14,15)$. Iron accumulation in these organs would then be analogous to that observed in atransferrinemia where an inability to transfer iron into transferrin results in excess ferrous iron accumulation in tissues (45). In contrast, the mechanisms of iron accumulation in the retina and brain are unknown. Taken together with the mechanisms noted above, the data presented here suggest that ceruloplasmin may function to promote iron efflux from cells in the central nervous system. The kinetics of biosynthesis, glycosylation, and secretion by glia data are identical to that observed for ceruloplasmin in hepatocytes $(1,2)$, supporting the concept of a similar extracellular role for this protein in the central nervous system. In the absence of this protein, iron would be unable to move into the brain extracellular fluid and CSF for eventual excretion. As indicated above, this process is normally slow and largely independent of the systemic circulation, and this would then account for the onset of symptoms later in life.

The mechanisms of brain injury and neuronal loss in aceruloplasminemia are also unknown. The degeneration of retinal photoreceptors and ganglion cells and the marked neuronal loss in the basal ganglia may result from oxidant induced freeradical generation associated with ferrous iron accumulation. Brain iron accumulation in association with neurologic symptoms has been observed in Hallervorden-Spatz disease, but the mechanisms of iron accumulation in the basal ganglia of these patients and the relationship of this to clinical symptoms is unknown (46). A direct role for iron-mediated tissue injury in the brain is supported by studies on the role of this metal in oxidant-mediated ischemia-reperfusion injury after stroke and cerebral hemorrhage and by data which demonstrate marked abnormalities in iron metabolism in a number of neurodegenerative disorders (47). In this regard, previous studies have revealed age-related decreases in human ceruloplasmin oxidase activity in the plasma, making it reasonable to speculate that such changes in the brain, in association with other environmental or genetic factors, may contribute to neurodegeneration observed with aging (48). In addition to iron accumulation, absence of ceruloplasmin ferroxidase activity in the retina and brain may result directly in tissue injury due to loss of an essential antioxidant function. This mechanism is consistent with recent studies that reveal a marked increase in plasma lipid peroxidation in patients with aceruloplasminemia (49).

The observation of murine ceruloplasmin expression in the same central nervous system tissues which are affected in patients with aceruloplasminemia suggests a direct role for the absence of local expression of this protein in the iron accumulation and tissue injury in this disorder. These findings are supported by observations which demonstrate the ineffectiveness of systemic chelation therapy in removing the brain iron or ameliorating symptoms in patients with aceruloplasminemia (13). Nevertheless, it remains possible that the central nervous system iron accumulation and tissue injury in this disease is dependent only upon the loss of plasma ferroxidase activity or a different previously characterized function of plasma ceruloplasmin (50). Clarification of this important issue will require the development of an animal model of aceruloplasminemia by homologous recombination, and such studies are currently in progress. The genetic characterization of aceruloplasminemia provides initial insight into the specific role of ceruloplasmin in iron metabolism in the brain. The data reported in this study suggest that further analysis of the function of ceruloplasmin within the central nervous system may be of value in elucidating the mechanisms of neuronal loss in aceruloplas- 
minemia and perhaps in other neurodegenerative disorders where abnormalities in iron metabolism have been demonstrated $(51,52)$.

\section{Acknowledgments}

We gratefully acknowledge the technical assistance of Mary Migas and thank David Holtzman and David Wilson for critical review of the manuscript.

This work was supported by funds from National Institutes of Health grant HL-41536 (J.D. Gitlin).

\section{References}

1. Sato, M., and J.D. Gitlin. 1991. Mechanisms of copper incorporation during the biosynthesis of human ceruloplasmin. J. Biol. Chem. 266:5128-5134.

2. Gitlin, J.D., J.J. Schroeder, L.M. Lee-Ambrose, and R.J. Cousins. 1992. Mechanisms of ceruloplasmin biosynthesis in normal and copper-deficient rats. Biochem. J. 282:835-839.

3. Bull, P.C., G.R. Thomas, J.M. Rommens, J.R. Forbes, and D.W. Cox. 1993. The Wilson disease gene is a putative copper transporting P-type ATPase similar to the Menkes gene. Nature Genet. 5:327-337.

4. Tanzi, R.E., K. Petrukhin, I. Chernov, J.L. Pellequer, W. Wasco, B. Ross, D.M. Romano, E. Parano, L. Pavone, L.M. Brzustowicz, et al. 1993. The Wilson disease gene is a copper transporting ATPase with homology to the Menkes disease gene. Nature Genet. 5:344-350.

5. Yamaguchi, Y., M.E. Heiny, and J.D. Gitlin. 1993. Isolation and characterization of a human liver cDNA as a candidate gene for Wilson disease. Biochem. Biophys. Res. Commun. 197:271-277.

6. Miyajima, H., Y. Nishimura, K. Mizoguchi, M. Sakamoto, T. Shimizu, and N. Honda. 1987. Familial apoceruloplasmin deficiency associated with blepharospasm and retinal degeneration. Neurology. 37:761-767.

7. Logan, J.I., K.B. Harveyson, G.B. Wisdom, A.E. Hughes, and G.P. Archbold. 1994. Hereditary caeruloplasmin deficiency, dementia and diabetes mellitus. Q. J. Med. 87:663-670.

8. Harris, Z.L., Y. Takahashi, H. Miyajima, M. Serizawa, R.T.A. MacGillivray, and J.D. Gitlin. 1995. Aceruloplasminemia: Molecular characterization of this disorder of iron metabolism. Proc. Natl. Acad. Sci. USA. 92:2539-2543.

9. Yoshida, K., K. Furihata, S. Takeda, A. Nakamura, K. Yamamoto, H. Morita, S. Hiyamuto, S. Ikeda, N. Shimizu, and N. Yanagisawa. 1995. A mutation in the ceruloplasmin gene is associated with systemic hemosiderosis in humans. Nature Genet. 9:267-272.

10. Takahashi, Y., H. Miyajima, S. Shirabe, S. Nagataki, A. Suenaga, and J.D. Gitlin. 1996. Characterization of a nonsense mutation in the ceruloplasmin gene resulting in diabetes and neurodegenerative disease. Hum. Mol. Genet. 5:81-84.

11. Harris, Z.L., M.C. Migas, A.E. Hughes, J.I. Logan, and J.D. Gitlin. 1996. Familial dementia due to a frameshift mutation in the caeruloplasmin gene. $Q$. J. Med. In press.

12. Daimon, M., T. Kato, T. Kawanami, M. Tominago, M. Igarashi, K. Yamatani, and H. Sasaki. 1995. A nonsense mutation of the ceruloplasmin gene in hereditary ceruloplasmin deficiency with diabetes mellitus. Biochem. Biophys. Res. Commun. 217:89-95.

13. Morita, H., S. Ikeda, K. Yamamoto, S. Morita, K. Yoshida, S. Nomoto, M. Kato, and N. Yanagisawa. 1995. Hereditary ceruloplasmin deficiency with hemosiderosis: a clinicopathological study of a Japanese family. Ann. Neurol. 37:646-656.

14. Osaki, S., and D.A. Johnson. 1969. Mobilization of liver iron by ferroxidase (ceruloplasmin). J. Biol. Chem. 244:5757-5758.

15. Roeser, H.P., G.R. Lee, S. Nacht, and G.E. Cartwright. 1970. The role of ceruloplasmin in iron metabolism. J. Clin. Invest . 49:2408-2417.

16. Askwith, C., D. Eide, A. Van Ho, P.S. Bernard, L. Li, S. Davis-Kaplan, D.M. Sipe, and J. Kaplan. 1994. The FET3 gene of S. Cerevisiae encodes a multicopper oxidase required for ferrous iron uptake. Cell. 75:403-410.

17. Yuan, D.S., R. Stearman, A. Dancis, T. Dunn, T. Beeler, and R.D. Klausner. 1995. The Menkes/Wilson disease gene homologue in yeast provides copper to a ceruloplasmin-like oxidase required for iron uptake. Proc. Natl. Acad. Sci. USA. 92:2632-2636.

18. Aldred, A.R., C.M. Brack, and G. Schreiber. 1995. The cerebral expression of plasma protein genes in different species. Comp. Biochem. Physiol. 111B:1-15.

19. Gitlin, J.D. 1988. Transcriptional regulation of ceruloplasmin gene expression during inflammation. J. Biol. Chem. 263:6281-6287.

20. Hackett, B.P., S.L. Brody, M. Liang, I.D. Zeitz, L.A. Bruns, and J.D. Gitlin. 1995. Primary structure of hepatocyte nuclear factor/forkhead homologue 4 and characterization of gene expression in the developing respiratory and reproductive epithelium. Proc. Natl. Acad. Sci. USA. 92:4249-4253.

21. Sanger, F.S., S. Nickless, and A.R. Coulson. 1977. DNA sequencing with chain-terminating inhibitors. Proc. Natl. Acad. Sci. USA. 74:5463-5476.

22. Chirgwin, J.M., A.E. Przybyla, R.J. Macdonald, and W.J. Rutter. 1979. Isolation of biologically active ribonucleic acid from sources enriched in ribonu- clease. Biochemistry. 18:5294-5299.

23. Fleming, R.E., and J.D. Gitlin. 1990. Primary structure of rat ceruloplasmin and analysis of tissue-specific gene expression during development. J. Biol. Chem. 265:7701-7707.

24. Simmons, D.M., J.L. Arriza, and L.W. Swanson. 1989. A complete protocol for in situ hybridization of messenger RNAs in brain and other tissues with radiolabeled single-stranded RNA probes. J. Histotech. 12:169-181.

25. Melton, D.A., P.A. Kreig, M.RT. Rebagliati, T. Maniatis, K. Zinn, and M.R. Green. 1984. Efficient in vitro synthesis of biologically active RNA and RNA hybridization probes from plasmids containing bacteriophage SP6 promoter. Nucleic Acids Res. 12:7035-7046.

26. Dugan, L.L., V.M.G. Bruno, S.M. Amagasu, and R.G. Giffard. 1995 Glia modulate the response of murine cortical neurons to excitotoxicity: glia exacerbate AMPA neurotoxicity. J. Neuroscience. 15:4545-4555.

27. Takahashi, N., T.L. Ortel, and F.W. Putnam. 1984. Single-chain structure of human ceruloplasmin: the complete amino acid sequence of the whole molecule. Proc. Natl. Acad. Sci. USA. 390:394-399.

28. Gelman, B.B. 1995. Iron in CNS disease. J. Neuropath. Exp. Neurol. 54: $477-486$.

29. Gorderick, V.R., G.D. McLaren, and W. Samowitz. 1994. Etiologies, consequences and treatment of iron overload. Crit. Rev. Clin. Lab. Sci. 31:89-133.

30. Dwork, A.J., G. Lawler, P.A. Zybert, M. Durkin, M. Osman, N. Willson, and A.I. Barkai. 1990. An autoradiographic study of the uptake and distribution of iron by the brain of the young rat. Brain Res. 518:31-39.

31. Dallman, P.R., and R.A. Spirito. 1977. Brain iron in the rat: extremely slow turnover in normal rats may explain long-lasting effects of early iron deficiency. J. Nutr. 107:1075-1081.

32. Bloch, B., T. Popovici, M.J. Levin, D. Treil, and A. Kahn. 1985. Transferrin gene expression visualized in oligodendrocytes of the rat brain by using in situ hybridization and immunohistochemistry. Proc. Natl. Acad. Sci. USA. 82: 6706-6710.

33. Sarthy, P.V., M. Fu, and J. Huang. 1989. Subcellular localization of an intermediate filament protein and its mRNA in glial cells. Mol. Cell. Biol. 9: 4556-4559.

34. Bradbury, M.W.B. 1984. The structure and function of the blood-brain barrier. Fed. Proc. 43:186-190.

35. Aldred, A.R., A. Grimes, G. Schreiber, and J.F.B. Mercer. 1987. Rat ceruloplasmin. Molecular cloning and gene expression in liver, choroid plexus, yolk sac, placenta, and testis. J. Biol. Chem. 262:2875-2878.

36. Zahs, K.R., V. Bigornia, and C.F. Deschepper. 1993. Characterization of "plasma proteins" secreted by cultured rat macroglial cells. Glia. 7:121-133.

37. Jaeger, J.L., N.A. Shimizu, and J.D. Gitlin. 1991. Tissue-specific ceruloplasmin gene expression in the mammary gland. Biochem. J. 280:671-677.

38. Yang, F.M., W.E. Friedrichs, R.L. Cupples, M.J. Bonifacio, J.A. Sanford, W.A. Horton, and B.H. Bowman. 1990. Human ceruloplasmin. Tissuespecific expression of transcripts produced by alternative splicing. J. Biol. Chem. 265:10780-10785.

39. Fleming, R., I. Whitman, and J.D. Gitlin. 1991. Induction of ceruloplasmin gene expression in the rat lung during inflammation and hyperoxia. Am. $J$ Physiol. 260:L68-L74.

40. Ehrenwald, E., and P.L. Fox. 1996. Role of endogenous ceruloplasmin in low density lipoprotein oxidation by human U937 monocytic cells. J. Clin. Invest. 97:884-890.

41. Yang, F., W.E. Friedrichs, L. deGraffenried, D.C. Herbert, F.J. Weaker, B.H. Bowman, and J.J. Coalson. 1996. Cellular expression of ceruloplasmin in baboon and mouse lung during development and inflammation. Am. J. Respir. Cell Mol. Biol. 14:161-169.

42. Pacht, E.R., and W.B. Davis. 1988. Role of transferrin and ceruloplasmin in antioxidant activity of lung epithelial lining fluid. J. Appl. Physiol. 64:2092-2099.

43. Gutteridge, J.M.C.. 1991. Plasma ascorbate levels and inhibition of the antioxidant activity of caeruloplasmin. Clin. Sci. 81:413-417.

44. Cornelissen, C.N., and F.P. Sparling. 1994. Iron piracy: acquisition of transferrin-bound iron by bacterial pathogens. Mol. Microb. 14:843-850.

45. Craven, E.M., J. Alexander, M. Eldridge, J.P. Kushner, S. Bernstein, and J. Kaplan. 1987. Tissue distribution and clearance kinetics of non-transferrin bound iron in the hypotransferrinemic mouse: a rodent model for hemochromatosis. Proc. Natl. Acad. Sci. USA. 84:3457-3461.

46. Swaiman, K.F. 1991. Hallervorden-Spatz syndrome and brain iron metabolism. Arch. Neurol. 48:1285-1293.

47. Dexter, D.T., P. Jenner, A.H.V. Schapira, and C.D. Marsden. 1992. Alterations in levels of iron, ferritin, and other trace metals in neurodegenerative diseases affecting the basal ganglia. Ann. Neurol. 32:S94-S100.

48. Musci, G., M.C. Bonaccorsi di Patti, U. Fagiola, and L. Calabrese. 1993 Age-related changes in human ceruloplasmin. J. Biol. Chem. 268:13388-13395.

49. Miyajima, H., Y. Takahashi, S. Masahiro, E. Kaneko, and J.D. Gitlin. 1996 Increased plasma lipid peroxidation in patients with aceruloplasminemia. Free Radical Biol. \& Med. 20:757-760.

50. Ehrenwald, E., G.M. Chiron, and P.L. Fox. 1994. Intact human ceruloplasmin oxidatively modifies low density lipoprotein. J. Clin. Invest. 93:1493-1501.

51. Connor, J.R., and A. Benkovic. 1992. Iron regulation in the brain: histochemical, biochemical, and molecular considerations. Ann. Neurol. 32:S51-S61.

52. Beard, J.L., J.R. Connor, and B.C. Jones. 1993. Iron in the brain. Nutr. Rev. 51:157-170. 